\title{
Patient's Satisfaction of Pharmacy Ambulatory Cares at the Emergency Hospital in Riyadh City, Saudi Arabia
}

\author{
Yousef Ahmed Alomi* iD, The Former \\ General Manager of General Administration \\ of Pharmaceutical Care, The Former Head, \\ National Clinical pharmacy and pharmacy \\ practice, The Former Head, Pharmacy R\&D \\ Administration, Ministry of Health, Riyadh, \\ SAUDI ARABIA. \\ Nahith Alotaibi, Head, Pharmacy Services, \\ Aleman Hopsital, Ministry of Health, Riyadh, \\ SAUDI ARABIA. \\ Hawazen Abdullah Al-Kammash, Clinical \\ Pharmacist Staff, General Administration \\ of Pharmaceutical Care, Ministry of Health, \\ Riyadh, SAUDI ARABIA \\ Aroub Alhamidi, Clinical Pharmacist Staff, \\ General Administration of Pharmaceutical \\ Care, Ministry of Health, Riyadh, SAUDI ARABIA \\ Walaa Aboziad, Clinical Pharmacist Staff, Gen- \\ eral Administration of Pharmaceutical Care, \\ Ministry of Health, Riyadh, SAUDI ARABIA. \\ Kairat Imad Al-Hennawi, Clinical Pharmacist \\ Staff, General Administration of Pharmaceuti- \\ cal Care, Ministry of Health, Riyadh, SAUDI \\ ARABIA. \\ Mohanad Imad Al-Hennawi, Clinical Pharma- \\ cist Staff, General Administration of Pharma- \\ ceutical Care, Ministry of Health, Riyadh, SAUDI \\ ARABIA.
}

\section{Correspondence:}

Dr. Yousef Ahmed Alomi, The Former General Manager of General Administration of Pharmaceutical Care, The Former Head, National Clinical pharmacy and pharmacy practice, The Former Head, Pharmacy R\&D Administration, Ministry of Health, Riyadh, Saudi Arabia.

Phone no: +966 504417712

E-mail:yalomi@gmail.com

Received: 03-01-2019;

Accepted: 27-03-2019

Copyright: (c) the author(s), publisher and licensee International Journal of Pharmacology and Clinical Sciences. This is an open-access article distributed under the terms of the Creative Commons Attribution Non-Commercial License, which permits unrestricted non-commercial use, distribution, and reproduction in any medium, provided the original work is properly cited.

This is an open access article distributed under the terms of the Creative Commons Attribution-NonCommercial-ShareAlike 4.0 License

Access this article online

www.ijpcs.net

DOI:

10.5530/ijphs.2019.8.34

\begin{abstract}
Purpose: To explore the patient satisfaction of pharmacy ambulatory care services at the Emergency Hospital in Riyadh city, Saudi Arabia. Methods: This is a 4-month cross-sectional survey of patients' satisfaction of ambulatory care pharmacy services at the Emergency Hospital, Saudi Arabia. The survey consisted of 48 questions divided into two parts: the first part collects demographic information and the second part contains questions on 11 domains: (1) medication availability (2) patient counseling (3) pharmacist and patient relationship (4) medication reconciliation (5) medication aberrance (6) pharmacy location (7) pharmacy-waiting area (8) pharmacy communications (9) pharmacy-waiting time (10) pharmacy recommends to others (11) overall patient satisfaction of pharmacy services. The survey was distributed to the Emergency Hospital in Riyadh city, included public, pediatrics and emergency hospitals ambulatory care patient. The study was in an electronic format and it analyze through the survey monkey system. Results: A total of 202 patients responded to the survey. Of those, $144(71.6 \%)$ was Saudi and $57(28.4 \%)$ was non-Saudi. The gender distribution 105 $(52 \%)$ were females and $97(48 \%)$ were males. The majority of them were in age group of $18-44$ years $(62 \%)$, while more than 44 years old was $68(33.7 \%)$. The highest level of education was high school $81(40.3 \%)$ followed by the Bachelor's degree 51 $(25.4 \%)$ and an intermediate school 44 (21.9\%). The mean [ \pm standard deviation (SD)] waiting time to get the medications was 19.36 \pm 11.02 (minute). The average scores of domains medication availability was 3.71 , patient counseling was 3.48 , pharmacist and patient relationship were 4.1 and medication reconciliation was 1.99 . The medication adherence was 1.88, pharmacy location was 4.13 , the pharmacy-waiting area was 3.31, pharmacy communications was 2.18, pharmacy-waiting time was 3.74 and pharmacy recommends to others was 3.69. The General evaluation of pharmacy services was found to be very good to excellent with $155(76.7 \%)$ of responders, while $186(92.1 \%)$ responders recommend the pharmacy to their family or friends and 176 $(88.44 \%)$ responders prefer to revisit pharmacy. Conclusion: More than half of the patients were satisfied with ambulatory care pharmacy services at Riyadh, Saudi Arabia. Medication reconciliation, medication adherence and pharmacy communication domains were not found to be satisfied. Refining ambulatory care pharmacy services will avoid drug misadventures, avoid extra cost and surge patient satisfaction with pharmacy services.
\end{abstract}

Keywords: Patient, Satisfaction, Ambulatory care, Pharmacy, Emergency, Ministry of Health, Saudi Arabia.

\section{INTRODUCTION}

Ambulatory or outpatient pharmacy practice is an essential part of the healthcare system that delivers pharmaceutical care to the patients who are not admitted to the hospital. Over more, two hundred Ministry of Health hospitals disturbed across all regions in King of Saudi Arabia. There are several types, hospitals specialties, including public hospital, pediatrics, maternity and obstetrics and gynecology, psychiatric and recently emergency hospital. All those institutions should implement patient satisfaction of pharmacy services as part of measuring tool of the pharmacy strategic plan of $\mathrm{MOH}$. At the emergency hospital their big receiving section, inpatient admission and ambulatory care clinic for common primary disease from diabetes Mellitus and cardiovascular illness. The ambulatory care service is a service provided for outpatients, including their pharmaceutical care, which plays a crucial role in the health care system. A stra- tegic plan of pharmaceutical care was published in 2012 at the Ministry of Health (MOH), Saudi Arabia and one of the measurements of follow-up assessment was patient satisfaction with regard to pharmacy services. Its part centered on providing the patient with appropriate knowledge, organizing patient's medication and building up relationships with patients and their families. ${ }^{[1]}$ Many factors are affecting patient satisfaction. Some elements are sociocultural, while others are linked to the health care services such as waiting in Emergency and explaining to the patient.

This study will focus on the factors related to health care service since they showed to have the significant contribution on the level of patient satisfaction, according to research published by Abolfotouh MA et al. ${ }^{[2]}$ Another study by Lobo Prabhu K et al. showed that a lower level of satisfaction is associated with the occurrence of postoperative surgical complication. ${ }^{[3]}$ Consequently, 
assessing patient satisfaction is essential as it is an integral part of measuring the quality of services provided. ${ }^{[3]}$ Therefore, evaluation of patients' satisfaction of pharmaceutical care including the emergency hospital has been an essential part of a standard assessment by the ministry of health in Saudi Arabia. ${ }^{[4]}$ Several works of literature in Saudi Arabia or elsewhere investigated patient satisfaction of pharmacy services at community pharmacy, ambulatory care clinics and primary care center. Most of the studies done non-emergency hospital and the various results of general patient satisfaction. Also, many studies have been conducted to measure the level of patients' satisfaction with pharmacy services. ${ }^{[5-8]}$ However, the majority of these studies were held in the USA and western countries with the non-emergency hospital.

To the best of our knowledge, there are no studies performed in the region of Riyadh at ambulatory pharmacy services of the $\mathrm{MOH}$ hospitals or any non-MOH governmental and even private hospitals in the Kingdom of Saudi Arabia. Therefore, conducting more studies regarding this field is necessary for Saudi Arabia since sociocultural variability might affect the result in a crucial way. ${ }^{[2]}$ Therefore, we aimed to explore the patient satisfaction in ambulatory care services at an emergency hospital in Riyadh city, the capital of Saudi Arabia.

\section{METHODS}

This is a 4-month cross-sectional survey of Patients satisfaction of Ambulatory care pharmacy services at in Emergency Hospital, Saudi Arabia. The survey consisted of 48 questions divided into two parts: the first part collects demographic information and the second part contains questions on 11 domains: (1) medication availability, (2) patient counseling, (3) pharmacist and patient relationship, (4) medication reconciliation, (5) medication aberrance, (6) pharmacy location, (7) pharmacywaiting area, (8) pharmacy communications, (9) Pharmacy-waiting time, (10) pharmacy recommends to others, (11) overall patient satisfaction of pharmacy services. We used the 5-point Likert response scale system to obtain responses. There were close-ended questions. The survey was distributed to the Emergency Hospital ambulatory care patient. The emergency hospital consisted of 280 beds, which will be extended to 500 beds in the future. The hospital consisted of huge emergency services for adults and pediatrics with adult and neonatal critical care services. The hospital has ambulatory care clinics and inpatient wards of adults surgical and medical in addition to materiality, medical and pediatric surgery. The hospital had pharmacy services through a very

\begin{tabular}{|c|c|c|}
\hline & $\begin{array}{l}\text { Response } \\
\text { Count }\end{array}$ & $\begin{array}{c}\text { Response } \\
\text { Percent }\end{array}$ \\
\hline \multicolumn{3}{|l|}{ Sex } \\
\hline Female & 105 & $52.0 \%$ \\
\hline Male & 97 & $48.0 \%$ \\
\hline Answered question & 202 & \\
\hline Skipped question & 0 & \\
\hline \multicolumn{3}{|l|}{ Nationality } \\
\hline Saudi & 144 & $71.6 \%$ \\
\hline Non-Saudi & 57 & $28.4 \%$ \\
\hline Answered question & 201 & \\
\hline Skipped question & 1 & \\
\hline \multicolumn{3}{|l|}{ Age } \\
\hline$<18$ & 7 & $3.5 \%$ \\
\hline $18-29$ & 56 & $27.7 \%$ \\
\hline $30-44$ & 71 & $35.1 \%$ \\
\hline $45-59$ & 65 & $32.2 \%$ \\
\hline $60+$ & 3 & $1.5 \%$ \\
\hline Answered question & 202 & \\
\hline Skipped question & 0 & \\
\hline $\begin{array}{l}\text { Qualification of the } \\
\text { responders }\end{array}$ & $\begin{array}{l}\text { Response } \\
\text { Count }\end{array}$ & $\begin{array}{c}\text { Response } \\
\text { Percent }\end{array}$ \\
\hline Doctorate degree & 0 & $0.0 \%$ \\
\hline Master degree & 4 & $2.0 \%$ \\
\hline Bachelor Degree & 51 & $25.4 \%$ \\
\hline Diploma & 7 & $3.5 \%$ \\
\hline High school & 81 & $40.3 \%$ \\
\hline Intermediate School & 44 & $21.9 \%$ \\
\hline Primary School & 12 & $6.0 \%$ \\
\hline Not educated & 2 & $1.0 \%$ \\
\hline Answered question & 201 & \\
\hline Skipped question & 1 & \\
\hline Type of visit & $\begin{array}{l}\text { Response } \\
\text { Count }\end{array}$ & $\begin{array}{c}\text { Response } \\
\text { Percent }\end{array}$ \\
\hline First visit & 53 & $26.8 \%$ \\
\hline Follow up & 145 & $73.2 \%$ \\
\hline Answered question & 198 & \\
\hline Skipped question & 4 & \\
\hline $\begin{array}{l}\text { In the last } 12 \\
\text { months, the number } \\
\text { of times visited the } \\
\text { pharmacy }\end{array}$ & $\begin{array}{c}\text { Response } \\
\text { Count }\end{array}$ & $\begin{array}{c}\text { Response } \\
\text { Percent }\end{array}$ \\
\hline None & 13 & $7.3 \%$ \\
\hline 1 time & 37 & $20.9 \%$ \\
\hline 2 & 22 & $12.4 \%$ \\
\hline 3 & 29 & $16.4 \%$ \\
\hline 4 & 34 & $19.2 \%$ \\
\hline 5 to 9 & 30 & $16.9 \%$ \\
\hline 10 or more times & 12 & $6.8 \%$ \\
\hline
\end{tabular}

\begin{tabular}{|c|c|c|}
\hline Answered question & 177 & \\
\hline Skipped question & 25 & \\
\hline $\begin{array}{l}\text { Time of Visiting the } \\
\text { Pharmacy }\end{array}$ & $\begin{array}{c}\text { Response } \\
\text { Count }\end{array}$ & $\begin{array}{l}\text { Response } \\
\text { Percent }\end{array}$ \\
\hline Morning & 137 & $69.2 \%$ \\
\hline Evening & 61 & $30.8 \%$ \\
\hline Night & 0 & $0.0 \%$ \\
\hline Answered question & 198 & \\
\hline Skipped question & 4 & \\
\hline $\begin{array}{l}\text { Average waiting } \\
\text { time to get the } \\
\text { medications }\end{array}$ & $\begin{array}{l}\text { Mean +/- SD } \\
\text { (minute) }\end{array}$ & \\
\hline $\begin{array}{l}\text { Ambulatory care } \\
\text { pharmacy of } \\
\text { Emergency hospital }\end{array}$ & $\begin{array}{c}19.36+/- \\
11.02\end{array}$ & \\
\hline Answered question & 191 & \\
\hline Skipped question & 11 & \\
\hline
\end{tabular}

comprehensive computerized physician order entry and the unit dose distribution system. The pharmacy consisted of inpatient pharmacy, emergency pharmacy and ambulatory care pharmacy services. The pharmacy provides clinical activities through total parental nutrition, medications safety and drug information services. The authors interviewed with an electronic survey documentation. The study was distributed in an electronic format and the data were analyzed through Survey Monkey system.

\section{RESULTS}

A total of 202 patients responded to the survey. Of those, $144(71.6 \%)$ was Saudi and 57 (28.4\%) was non-Saudi. There were 105 (52\%) females and 97 (48\%) were males. The majority of them were in age group 18-44 years (62\%), while more than 44 years old was 68 (33.7\%). The highest level of education was high school 81 (40.3\%) followed by the Bachelor's degree 51 (25.4\%) and an intermediate school 44 (21.9\%). Most of the patients visited the pharmacy 3 to 9 times in the past 12 months 93 (52.5\%) with $145(73.2 \%)$ follow up visit, whereas the others 53 (26.8\%) visited the pharmacy for the first time. Most of the patients visited the pharmacy on morning duty 137 (69.2\%), while 61 (30.8\%) attended the pharmacy at evening duty. The mean $[ \pm$ Standard Deviation (SD)] waiting time to get the medications was $19.36 \pm 11.02$ (minute) (Table 1). The average scores of domains medication availability was 3.71 , patient counseling was 3.48 , pharmacist and patient relationship was 4.1 and medication reconciliation was 1.99 . The medication adherence was 1.88 , pharmacy location was 4.13 , the pharmacywaiting area was 3.31 , pharmacy communica- 


\section{Table 2: Patient satisfaction domains}

\section{Answer Options}

\section{A. Medication Availability Domain}

Have you received all the medications, that has been prescribed to you

You have received a prescription refill of your medicines to continue

dispensing from pharmacy directly next months.

\begin{tabular}{|l|l|l|l|l|c|c}
$\begin{array}{l}\text { Very } \\
\text { poor }\end{array}$ & Poor & Good & Very good & Excellent & $\begin{array}{c}\text { Rating } \\
\text { Average }\end{array}$ & $\begin{array}{c}\text { Response } \\
\text { Count }\end{array}$ \\
\hline
\end{tabular}

C. Patient Counselling Domain

All medications you received were packed.

Instructions were labeled on each medication

Instructions that contain of: (patient's name, medication's name,

medication's strength, and how to use) were written clearly.

The pharmacist provides you written/ or printed information about drug

therapy and/or diseases.

The pharmacist Explains to you how to know if medications are working

The pharmacist explains all the possible side effects

The pharmacist provides you information about the proper storage of your medication.

The pharmacist provides you with thorough medication counseling and encourages you to ask questions.

You understand what pharmacist saying

\begin{tabular}{|c|c|c|}
\hline 1 & 57 & 46 \\
\hline 0 & 9 & 44 \\
\hline 0 & 1 & 6 \\
\hline 0 & 3 & 11 \\
\hline 0 & 1 & 42 \\
\hline 3 & 99 & 72 \\
\hline 18 & 86 & 81 \\
\hline 24 & 157 & 14 \\
\hline 32 & 71 & 49 \\
\hline 3 & 14 & 39 \\
\hline 0 & 2 & 26 \\
\hline
\end{tabular}

answered question

skipped question

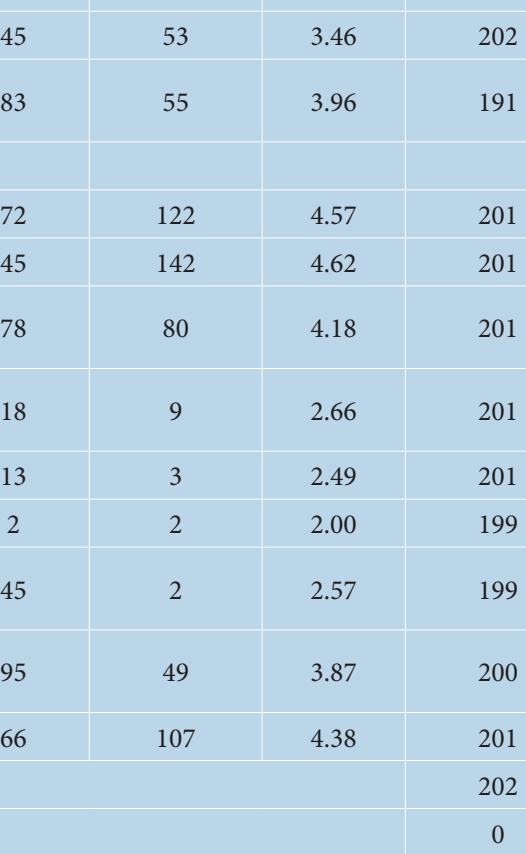

Table 3: Patient satisfaction domains

Answer Options

Very poor

Poor

Good

Very good

Excellent

Rating

Average

Response Count

C. Pharmacist and Patient Relationship Domain

When you're receiving your prescription medications, the pharmacist delivers your medicines in a polite way

Pharmacists have technical skills (thoroughness, carefulness, competence).

All pharmacists characterized with courtesy and respect.

The way the pharmacist answers your questions excellent.

The amount of time the pharmacist spends with you.

E. Medication Reconciliation Domain

Pharmacist uses information about you previous conditions/drugs when assessing your drug therapy.

You have received a copy of prescription contains all medications prescribed to you, and may use during outpatient

F. Medication Adherence Domain

the pharmacist ask about medication compliance

Did the pharmacist follow up you and call you after taking your medications as prescribed

\begin{tabular}{|c|c|c|c|c|c|c|}
\hline 0 & 6 & 21 & 93 & 82 & 4.24 & 202 \\
\hline 0 & 2 & 30 & 87 & 81 & 4.24 & 200 \\
\hline 1 & 18 & 42 & 74 & 65 & 3.92 & 200 \\
\hline 0 & 0 & 21 & 110 & 67 & 4.23 & 198 \\
\hline 0 & 3 & 48 & 119 & 29 & 3.87 & 199 \\
\hline 8 & 186 & 5 & 1 & 0 & 2.00 & 200 \\
\hline 27 & 148 & 4 & 5 & 3 & 1.98 & 187 \\
\hline & & & & & & \\
\hline 28 & 152 & 19 & 3 & 0 & 1.99 & 202 \\
\hline
\end{tabular}

answered question

skipped question

tions was 2.18, pharmacy-waiting time was 3.74 and pharmacy recommends to others was 3.69 (Table 2 and 3). The General evaluation of pharmacy services was found to be very good to excellent with $155(76.7 \%)$ of responders, while 186 (92.1\%) responders recommend the pharmacy to their family or friends and 176 (88.44\%) responders prefer to revisit phar- macy. The majority of patients had very satisfied 56 (31.5\%), some satisfied with pharmacy services 73 (41\%) or neither satisfied nor happy 
Table 4: Patient satisfaction domains

G.Pharmacy Location Domain

The pharmacy conveniently located

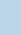

H. Pharmacy Waiting Area Domain

The waiting area of pharmacy comfortable, convenient pharmacy lounge?

The amount of time you have been waiting before seeing a pharmacist was

The place of pharmaceutical counseling respects your privacy.

I. Pharmacy Communication Domain

Getting through to the pharmacy by phone

J. Pharmacy Waiting Time Domain

The amount of time it takes to get a prescription filled at your pharmacy.

\begin{tabular}{|c|c|c|c|c|c|c|}
\hline 0 & 6 & 31 & 94 & 69 & 4.13 & 200 \\
\hline 36 & 59 & 44 & 39 & 23 & 2.77 & 201 \\
\hline 0 & 8 & 49 & 126 & 18 & 3.77 & 201 \\
\hline 5 & 18 & 83 & 80 & 14 & 3.40 & 200 \\
\hline 7 & 135 & 33 & 3 & 0 & 2.18 & 178 \\
\hline 0 & 8 & 45 & 141 & 8 & 3.74 & 202 \\
\hline 1 & 7 & 51 & 138 & 5 & 3.69 & 202 \\
\hline 0 & 13 & 54 & 101 & 34 & 3.77 & 202 \\
\hline 3 & 11 & 50 & 126 & 9 & 3.64 & 199 \\
\hline & & & & & & 202 \\
\hline & & & & & & 0 \\
\hline
\end{tabular}

Table 5: Overall, satisfied or dissatisfied with your last visit to our pharmacy

\begin{tabular}{|c|c|c|}
\hline Answer Options & $\begin{array}{c}\text { Response } \\
\text { Count }\end{array}$ & $\begin{array}{c}\text { Response } \\
\text { Percent }\end{array}$ \\
\hline Very satisfied & 56 & $31.5 \%$ \\
\hline $\begin{array}{c}\text { Somewhat satisfied } \\
\text { Neither satisfied nor } \\
\text { dissatisfied }\end{array}$ & 73 & $41.0 \%$ \\
\hline Somewhat dissatisfied & 4 & $23.0 \%$ \\
\hline Very dissatisfied & 4 & $2.2 \%$ \\
\hline Answered question & 178 & \\
\hline Skipped question & 24 & \\
\hline
\end{tabular}

with pharmacy services was 41 (23\%) (Table 4 and 5).

\section{DISCUSSION}

In this study, we evaluated the patients' opinion about pharmaceutical care in ambulatory care services at emergency hospital for four months in the city of Riyadh, Saudi Arabia. Around two hundred patients responded to our questionnaire, which felled within the range required for our study to decrease the error margin that could happen. ${ }^{[7,9-11]}$ We categorized domains that were identified from the questionnaire to improve the analysis of results. The majority of respondents are Saudis as they receive their health insurance in the governmental sector, while the only a small portion of nonSaudis is allowed to receive their insurance there. Gender distribution was almost equally as expected. The majority of the participants are middle-aged (18-44) followed by old aged $(+44)$ since old age patients have more difficulties accessing healthcare services. Waiting time is one of the most important factors regarding patient satisfaction; this domain was found to be significant among the hospital, which is related to the differences in the distribution of the organization system and the number of pharmacy staff at the hospital. Waiting time was considered a major factor in determining patient's satisfaction, especially in the emergency department. Waiting time was found to be acceptable in our study since it fell below 30 min, similar results were obtained by another study conducted in Singapore. ${ }^{[12]}$

Both pharmacist-patient relationships and patient counseling have a high level of satisfaction. However, there is the lowest rating in areas like explaining adverse effects and the expected outcome of each medication. The lowest score in explanation might be due to an increased number of patients in the emergency department, which will result in decreasing the time spent with each patient. ${ }^{[4]}$ Although the Medication availability domain rating is high, another study conducted in primary health care centers was higher. The fewer patients in primary care centers allow pharmacists to spend more time with the patients who most probably is the attributed factor behind the higher rate in primary health care centers. ${ }^{[4,9,10]}$ The medication reconciliation domain has not been supported in all hospital yet; therefore, the results show low satisfaction as expected. Nevertheless, the results are accepted compared to international results. ${ }^{[4,7,9,10]}$ Other domains such as waiting area, pharmacy communication and pharmacy location, although they fell into international studies and some of them are below average. The majority of patients participated in this study to assess the pharmacy services in an emergency hospital in Riyadh city as very well and some of them might recommend it to family members and friends..$^{[4,6,8-10]}$ This study could act as a basis in identifying the areas of weakness in emergency hospitals in Riyadh city to improve them in the future.

\section{CONCLUSION}

Although patient satisfaction of pharmacy ambulatory care services exceeds more than half of the responders, there were several domains that need to be improved to reach an optimal level of patient satisfaction. Medication reconciliation, medication adherence and pharmacy communications need additional improvement. In future studies, we intend to 
adjust these parameters and annual monitoring of patient satisfaction will improve the patient's clinical outcomes and prevent drug-related problems at the $\mathrm{MOH}$ hospitals in the Kingdom of Saudi Arabia.

\section{ACKNOWLEDGMENT}

None.

\section{CONFLICT OF INTEREST}

The authors declare that there are no conflicts of interest.

\section{ABBREVIATIONS}

KSA: Kingdom of Saudi Arabia; MOH: Ministry of Health; USA: United States of America.

\section{ORCID ID}

Yousef Ahmed Alomi (iD https://orcid.
org/0000-0003-1381-628X

\section{REFERENCES}

1. Board of Pharmaceutical Specialities. Ambulatory Care Pharmacy. Americn Pharm Assoc. 2013;2011-2.

2. Abolfotouh MA, Al-Assiri MH, Alshahrani RT, Almutairi ZM, Hijazi RA, Alaskar AS. Predictors of patient satisfaction in an emergency care centre in central Saudi Arabia: A prospective study. Emerg Med J. 2017;34(1):27-33.

3. Lobo PK, Cleghorn MC, Elnahas A, Tse A, Maeda A, Quereshy FA, et al. Is quality important to our patients? The relationship between surgical outcomes and patient satisfaction. BMJ Qual Saf. 2018;27(1):48-52.

4. Alomi YA, Alghamdi SJ, Alattyh RA. Strategic plan of general administration of pharmaceutical care at ministry of health in Saudi Arabia 2012-2022. J Pharm Pharm Scien. 2015;1(13):1-8.

5. Al-Arifi MN. Patients' perception, views and satisfaction with pharmacists' role as health care provider in community pharmacy setting at Riyadh, Saudi Arabia. Saudi Pharm J. 2012;20(4):323-30.

6. Al-Jumah KA, Hassali MA, Al-Zaagi I. Adaptation and validation of a questionnaire assessing patient satisfaction with pharmacy services in general hospitals. Patient Prefer Adherence. 2014;8:371-5.
7. Al-Jumah KA, Hassali MA, Alzaagi I. Patient satisfaction with the health services provided by the pharmacist at a general hospital in Riyadh, Saudi Arabia. Eur J Pers Centered Health. 2014;2(4):517.

8. Alturki M, Khan TM. A study investigating the level of satisfaction with the health services provided by the Pharmacist at ENT hospital, Eastern Region Alahsah, Kingdom of Saudi Arabia. Saudi Pharm J. 2013;21(3):255-60.

9. Surur AS, Teni FS, Girmay G, Moges E, Tesfa M, Abraha M. Satisfaction of clients with the services of an outpatient pharmacy at a university hospital in northwestern Ethiopia: a cross-sectional study. BMC Health Serv Res. 2015;15(1):229.

10. Oparah AC, Kikanme LC. Consumer satisfaction with community pharmacies in Warri, Nigeria. Res Soc Adm Pharm. 2006;2(4):499-511.

11. Holsclaw $\mathrm{SL}$, Olson $\mathrm{KL}$, Hornak $\mathrm{R}$, Denham AM. Assessment of patient satisfaction with telephone and mail interventions provided by a clinical pharmacy cardiac risk reduction service. J Manag Care Pharm. 2005;11(5):403-9.

12. Tam VHY, Lim MM. Patients' perceptions and expectations of outpatient pharmacy services in a teaching hospital. Int J Pharm Pract. $1997 ; 5(3): 128-32$ 